\title{
Alcohol Use, Stigmatizing/Discriminatory Attitudes, and HIV High-Risk Sexual Behaviors among Men Who Have Sex with Men in China
}

\author{
Meizhen Liao, ${ }^{1}$ Dianmin Kang, ${ }^{1}$ Xiaorun Tao, ${ }^{1}$ Jennifer Huang Bouey, ${ }^{2}$ \\ Muktar H. Aliyu, ${ }^{3,4}$ Yuesheng Qian, ${ }^{1}$ Guoyong Wang, ${ }^{1}$ Xiaoguang Sun, \\ Bin Lin, ${ }^{1}$ Zhenqiang Bi, ${ }^{1}$ and Yujiang Jia ${ }^{3}$ \\ ${ }^{1}$ Institution for HIV/AIDS Control and Prevention and Shandong Key Laboratory for Epidemic Disease Control and \\ Prevention, Shandong Center for Disease Control and Prevention, Jinan, Shandong 250014, China \\ ${ }^{2}$ Department of International Health, Georgetown University, Washington, DC 20057, USA \\ ${ }^{3}$ Department of Preventive Medicine, Vanderbilt University School of Medicine, Nashville, TN 37232, USA \\ ${ }^{4}$ Vanderbilt Institute for Global Health, Vanderbilt University, Nashville, TN 37232, USA
}

Correspondence should be addressed to Dianmin Kang; dmkang@sohu.com and Yujiang Jia; jiayj@aol.com

Received 19 October 2013; Accepted 22 February 2014; Published 27 March 2014

Academic Editor: Muktar Aliyu

Copyright (C) 2014 Meizhen Liao et al. This is an open access article distributed under the Creative Commons Attribution License, which permits unrestricted use, distribution, and reproduction in any medium, provided the original work is properly cited.

Objective. This research was conducted to assess the correlates of alcohol consumption and HIV/AIDS-related stigmatizing and discriminatory attitudes among men who have sex with men (MSM) in Shandong province, China. Methods. A cross-sectional survey provided demographics, sexual behaviors, illicit drug use, alcohol consumptions, and service utilization. Results. Of 1,230 participants, $82.8 \%$ were single, $85.7 \%$ aged $<35$ years, $47.2 \%$ had college or higher education, and $11.7 \%$ drank alcohol $>3$ times per week in the past six months. The average total score of stigmatizing and discriminatory attitude was $37.4 \pm 4.4$. More frequent episodes of alcohol use were independently associated with higher levels of HIV/AIDS-related stigma and discrimination, unprotected anal sex, bisexual identity, multiple male sex partners, drug use, and lower levels of education. Expressing higher levels of HIV/AIDS-related stigmatizing and discriminatory attitudes was independently associated with alcohol use, unprotected male anal sex, bisexuals, more male sex partners, commercial sex with men, and non-receipt of peer education in the past year. Conclusion. HIV/AIDS-related stigmatizing and discriminatory attitudes are common and associated with alcohol use and unprotected sex among MSM. The finding highlights the needs to develop programs that would reduce HIV/AIDS-related stigmatizing and discriminatory attitudes and strengthen alcohol use prevention and risk reduction initiatives among MSM.

\section{Introduction}

The rapid rise in HIV prevalence among men who have sex with men (MSM) in many cities across the nation has drawn attention to the dynamics of the HIV epidemic in China [1$3]$. It is estimated that about $2.2 \%$ of Chinese adult males had sex with another male [4]. According to the 2011 estimates for the HIV/AIDS epidemic in China, $81.6 \%$ of $48,000 \mathrm{HIV}$ new cases were infected through sexual contact, $29.4 \%$ of those infected from sexual contact were through homosexual contact [2]. Under the strong influence of Confucianism and collectivism, Chinese traditional culture emphasizes familial responsibilities; MSM behaviors are highly stigmatized and MSM face strong social pressure to hide their identity [5]. On the other hand, stigma surrounding HIV/AIDS has been shown to act as a barrier to HIV prevention, treatment, and care $[6,7]$. People who hold stigmatizing attitudes are also less likely to adopt preventive behaviors and more likely to have multiple sexual partners, a commercial sex partner, and some other HIV-related high-risk behaviors [8, 9].

Alcohol consumption has increased considerably in China in the past three decades, accompanying a rapidly expanding economy, urbanization, and globalization [10]. The global literature suggests that alcohol consumption is 
associated with a number of sexual risk behaviors and outcomes, including premarital intercourse, multiple sexual partners, and unprotected sex $[11,12]$. As the most commonly used legal substance, drinking-related exposures to sexual risk behaviors and drinkers' increased biological susceptibility could lead to an increased risk of HIV and other sexually transmitted infections (STIs) [11]. Drink and HIV-related stigma/discrimination are common in the MSM community. Understanding the relationship between stigma, alcohol use, and sexual behavior among MSM has important intervention implications. The purpose of this study is to assess correlates for alcohol use and HIV/AIDS-related stigmatizing and discriminatory attitudes among MSM in Shandong province, China.

\section{Methods}

2.1. Study Participants. A cross-sectional study was conducted among MSM to collect demographic, sexual behaviors, illicit drug use, alcohol consumptions, and health service utilization by local Center for Disease Control and Prevention (CDC) in three cities, Jinan, Qingdao, and Yantai, in Shandong province, China, from April to June in 2011. Prior to the recruitment of the participants, we conducted informative research including in-depth interviews with key informants to gather the background information among MSM, the venues to access them, and selection of the candidates of the first group for interview. Participants were recruited from gay-oriented venues such as bars, night clubs, tea houses, bathhouses, saunas, public parks and bathrooms, outdoor cruising areas, and HIV testing sites. After these initial participants were approached and interviewed by trained public health staff, we asked the participants to refer their peers to attend the study. A mixed recruitment method, including community outreach, venue-based recruitment, and internet advertisement, was also applied in the study. All potential participants were invited for eligibility assessments. The enrollment criteria included male, 18 years of age or older, self-reported ever having sex with another male in the past 12 months, and willing to complete the study. Survey information was collected anonymously and handled in a confidential manner. Verbal informed consent was obtained from all participants before the interview. Voluntary participation, anonymity, and confidentiality were ensured for all participants. The study was approved by the Institutional Review Board of Shandong Center for Disease Control and Prevention.

2.2. Measures. Structured questionnaire-based interviews provided demographics (age, marital status, ethnicity, residency status and education, sexual, drug use, and alcohol drinking behaviors, access and utilization of HIV-related prevention services, and stigma and discriminatory attitudes towards People Living With HIV/AIDS (PLWHA)). The term "bisexual" was used for participants who were married or cohabiting with women or reported ever having sex with a woman in the past 6 months. Attitudes towards PLWHA were measured by asking participants about their agreement/disagreement ( 1 = "yes," 2 = "no") with 22 statements [13]. The scale was adapted from two pilot investigations tested in Thailand and Zimbabwe and measured 3 dimensions of HIV/AIDS-related stigma and discrimination: shame, blame, and social isolation; perceived discrimination; and equity. The reliability (alpha) of the stigma measure was 0.83 . The scale included questions such as "People living with HIV/AIDS should be ashamed"; "People living with HIV/AIDS face neglect from their family"; "People living with HIV/AIDS do not deserve any support." Items were summed to create total scale scores, with a range of 22-44 where a higher score means lower stigma and lower score indicates a higher stigma. Frequency of alcohol use was determined directly from responses to a single questionnaire item in which respondents were asked how often they drank in the past six months. Responses included "about every day," "5-6 days a week," "3-4 days a week," "1-2 days a week," "2-3 days a month," "less often than monthly," and "never." In the final analysis, the categories "About every day," "5-6 days a week," and "3-4 days a week" were collapsed into a single variable "more than 3 days per week," because of the low frequencies of individual responses when the original categories were considered separately. Serum samples were screened for HIV1 antibodies by enzyme-linked immunosorbent assay (ELISA; Vironostika HIV Uni-Form plus O, bioMerieux, Holland) and confirmed by Western Blot test (HIV Blot $2.2 \mathrm{WB}$, Genelabs Diagnostics). Syphilis screening was performed by rapid plasma regain (RPR; Shanghai Rongsheng, China) and confirmed by Treponema pallidum particle assay test (TPPA; Fujirebioinc, Japan). Pre- and posttesting counseling were provided by local CDC.

2.3. Statistical Analysis. Survey data and blood testing results were recorded and assessed for congruency using EpiData software (EpiData 6.4 for Windows, the EpiData Association Odense, Denmark). The Statistical Program for Social Sciences software (SPSS software, Version 15.0; SPSS Inc., Chicago, IL, US) was utilized for all analyses. Univariate analyses were conducted for demographic, sexual, drug use, and drinking variables and related prevention services. Multivariable logistic regression analyses were conducted using a stepwise backward sequence. Variables with $P<$ 0.05 in multivariable analysis were determined as statistically significant. Multiple linear regression analysis was applied to determine which predictors were independently associated with total stigma scale scores after controlling for potential confounders.

\section{Results}

3.1. Characteristics of Participants. Of 1,230 eligible participants, $82.8 \%$ were single, $85.7 \%$ were between 18 and 35 years of age, nearly half (47.2\%) had college or higher levels of education, $28.6 \%$ were married or cohabiting with women or reported ever having sex with women in the past 6 months. More than two-thirds of respondents (68.7\%) identified themselves as homosexual, a quarter (26.3\%) identified 


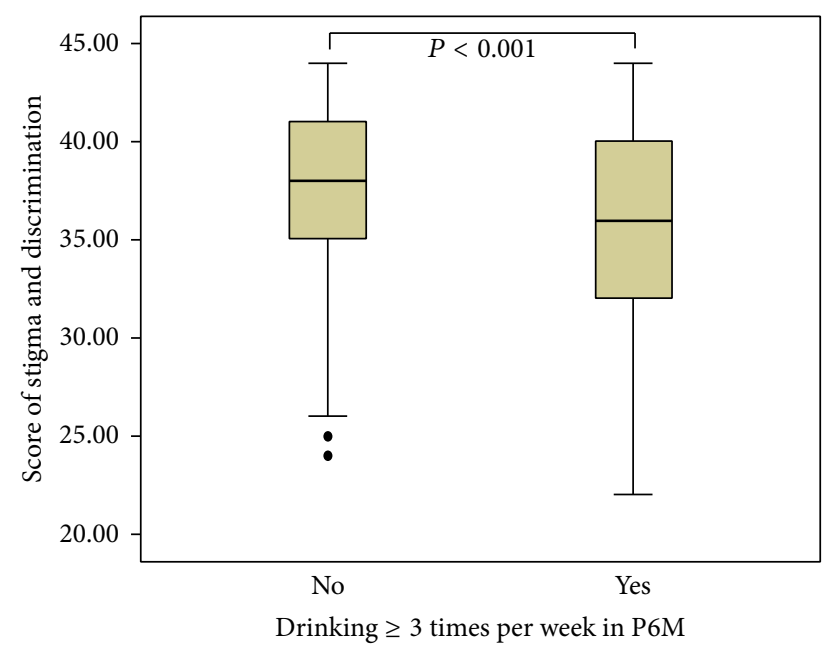

FIgURE 1: Comparisons of HIV/AIDS-related stigmatizing and discriminatory attitudes with the alcohol consumption for the participants who reported drinking $\geq 3$ times per week in the past 6 months (P6M) in Shandong province, China.

themselves as bisexual, and $1.4 \%$ identified themselves as heterosexual; $19.4 \%$ were non-Shandong province residents, and $2.0 \%$ belonged to a non-Han minority ethnic group (Table 1).

3.2. Sexual Behaviors and Prevalence Rates of HIV and Syphilis. Approximately $91.4 \%$ of participants reported having had sex with men in the past six months, $54.3 \%$ had more than two male sex partners in the past week, $70.8 \%$ used a condom at last anal sex, and $31.3 \%$ consistently used condoms in the past 6 months with male partners. In addition, 27.2\% of respondents admitted having had commercial sex with men, with only $29.8 \%$ reporting consistent condoms use in the past 6 months. Further, 21.5\% of participants reported ever selling sex to another man, with only $31.1 \%$ of them reporting consistent condom use in the past 6 months. About one-quarter of respondents (23.4\%) had sex with a female in the past 6 months, with one-third (32.5\%) reporting consistent condom use over the same time period. Only $1.1 \%$ of participants reported ever using illicit drugs. Approximately half $(50.7 \%)$ of participants received HIV testing in the past year, and three-quarters $(75.2 \%)$ and $41.3 \%$ received condom promotion/HIV testing and counseling and peer education, respectively. Of all participants, $1.6 \%$ were HIV-infected and $6.8 \%$ were syphilis-infected (Table 2 ).

3.3. Correlates for Drinking Behaviors. Of the participants, $11.7 \%$ reported drinking alcohol $\geq 3$ times per week in the past 6 months. Multivariable logistic regression analysis that indicated drinking behaviors was associated with higher levels of HIV/AIDS-related stigma and discrimination $(\mathrm{AOR}=0.92$, 95\% CI: 0.87-0.96), unprotected male anal sex in the past 6 months (AOR $=1.9,95 \%$ CI: 1.1-3.3), bisexual identity (AOR $=2.2,95 \% \mathrm{CI}: 1.3-3.9)$, more male sex partners in the past week $(\mathrm{AOR}=1.5,95 \% \mathrm{CI}: 1.0-2.4 ; \geq 2)$, drug use $(\mathrm{AOR}=6.7$,
95\% CI: 2.0-22.3), and high school or lower education level $(\mathrm{AOR}=1.6,95 \% \mathrm{CI}: 1.0-2.6)$ (Table 3).

3.4. Correlates for Stigma and Discrimination. The total score for stigmatizing and discriminatory attitudes among participants was $37.4 \pm 4.4$, ranging from 22 to 44 . The multivariate linear regression model indicated that MSM who drank alcohol $\geq 3$ times per week in the past 6 months (A $\beta=1.5,95 \%$ CI: $0.8-2.3$ ), had unprotected male anal sex in the past 6 months $(\mathrm{A} \beta=1.7,95 \% \mathrm{CI}$ : 1.1-2.2), have bisexual identity $(\mathrm{A} \beta=0.9,95 \% \mathrm{CI}$ : 0.4-1.4), had more male sex partners in past week (A $\beta=1.9,95 \% \mathrm{CI}: 1.3-2.4 ; \geq 2)$, had commercial sex with man in the past 6 months $(\mathrm{A} \beta=0.8$, 95\% CI: 0.2-1.4), and are non-receipt of peer education in the past year ( $\mathrm{A} \beta=1.7,95 \% \mathrm{CI}$ : $1.2-2.2)$ were more likely to have lower HIV/AIDS-related stigma/discrimination score and thus exhibit more negative attitudes (Table 3, Figure 1).

\section{Discussion}

To the best of our knowledge, this is the first study from China that assesses HIV/AIDS-related stigmatizing and discriminatory attitudes and its relationship with alcohol consumption among MSM. This study revealed that HIV/AIDSrelated stigmatizing and discriminatory attitudes were common among MSM and associated with drinking behavior, unprotected anal sex, and commercial sex among MSM in Shandong province, China. Confronting a rapid rise of HIV incidence among MSM in China, common negative attitudes towards PLWHA, excessive alcohol use behaviors, and bisexual and unprotected sex among this group have become emerging challenges in containing the epidemic. Stigma is particularly relevant to prevention and treatment in the HIV/AIDS pandemic [14]. The negative attitudes towards persons living with HIV/AIDS (PLWHA) are often associated with self-imposed isolation that results from individuals' reluctance to access services due to fear that family and community members may shun them for their drinking and drug use behaviors $[15,16]$. On the other hand, Chinese cultural norms encourage social drinking. Alcohol is commonly consumed in social settings, particularly by men, as a normal part of their social life, to identify with new friends, maintain good relations, and celebrate events among friends. Other researchers have shown a consistent association between alcohol use and several sexual risk behaviors and HIV/STIs across both high-risk groups and general populations in China $[17,18]$. Hence, in confronting the rapid expansion of the HIV/AIDS epidemic among MSM in China, the findings of the present study underline the urgent need to reduce the stigmatizing and discriminatory attitudes towards PLWHA and call for the need for alcohol use prevention and risk reduction among MSM communities.

This study shows that self-identification as bisexual is independently associated with drinking behaviors and with more negative attitudes towards PLWHA. Shandong is the second most populous province in China and the home of Confucius. Under the strong influence of Confucianism and collectivism, MSM behaviors are stigmatized and MSM face 
TABLE 1: Demographics and biological outcomes among men who have sex with men in Shandong province, China.

\begin{tabular}{|c|c|c|c|c|c|}
\hline \multirow{2}{*}{ Variables } & \multicolumn{2}{|c|}{ Total } & \multicolumn{2}{|c|}{ Drinking ( $\geq 3$ times/week) } & \multirow{2}{*}{$\begin{array}{c}\text { Stigma and discrimination } \\
\pm \mathrm{SD}\end{array}$} \\
\hline & $N$ & $\%$ & $N$ & $\%$ & \\
\hline Total & 1230 & & 144 & 11.7 & $37.4 \pm 4.4$ \\
\hline \multicolumn{6}{|l|}{ Demographics } \\
\hline \multicolumn{6}{|l|}{ Study sites } \\
\hline Jinan & 400 & 32.5 & 48 & 12.0 & $39.0 \pm 3.8$ \\
\hline Qingdao & 400 & 32.5 & 55 & 13.7 & $33.8 \pm 3.8^{\ddagger}$ \\
\hline Yantai & 430 & 35.0 & 41 & 9.5 & $39.4 \pm 2.9$ \\
\hline \multicolumn{6}{|l|}{ Recruited venue } \\
\hline Bars, night clubs, or tea houses & 329 & 26.7 & 49 & 14.9 & $36.7 \pm 4.2$ \\
\hline Bathhouses or sauna & 161 & 13.1 & 24 & 14.9 & $33.8 \pm 3.8^{\ddagger}$ \\
\hline Outdoor cruising area & 98 & 8.0 & 11 & 11.2 & $34.1 \pm 3.9^{\ddagger}$ \\
\hline Internet or HIV testing sites & 642 & 52.2 & 60 & 9.3 & $39.2 \pm 3.6$ \\
\hline \multicolumn{6}{|l|}{ Age (years) } \\
\hline$<25$ & 548 & 44.6 & 53 & 9.7 & $37.8 \pm 4.2$ \\
\hline $25-34$ & 505 & 41.1 & 50 & 9.9 & $37.4 \pm 4.4$ \\
\hline$\geq 35$ & 177 & 14.3 & 41 & $23.2^{\ddagger}$ & $36.1 \pm 4.6^{\ddagger}$ \\
\hline \multicolumn{6}{|l|}{ Marital status } \\
\hline Single/separated & 1018 & 82.8 & 97 & 9.5 & $37.7 \pm 4.2$ \\
\hline Married or cohabitating & 212 & 17.2 & 47 & $22.2^{\ddagger}$ & $35.9 \pm 4.6^{\ddagger}$ \\
\hline \multicolumn{6}{|l|}{ Residency } \\
\hline Shandong province & 991 & 80.6 & 107 & 10.8 & $37.4 \pm 4.4$ \\
\hline Non-Shandong province & 239 & 19.4 & 37 & 15.5 & $37.6 \pm 4.2$ \\
\hline \multicolumn{6}{|l|}{ Ethnicity group } \\
\hline Han & 1206 & 98.0 & 140 & 11.6 & $37.4 \pm 4.4$ \\
\hline Others & 24 & 2.0 & 4 & 16.7 & $38.8 \pm 3.5$ \\
\hline \multicolumn{6}{|l|}{ Occupation } \\
\hline Student & 187 & 15.2 & 6 & 3.2 & $38.3 \pm 4.3$ \\
\hline Commercial service & 539 & 43.8 & 80 & 14.8 & $37.7 \pm 4.2$ \\
\hline Farmer & 117 & 9.5 & 8 & 6.8 & $38.9 \pm 4.0$ \\
\hline Full time employee & 268 & 21.8 & 33 & $22.9^{\ddagger}$ & $37.0 \pm 4.3$ \\
\hline Housework and/or unemployed & 119 & 9.7 & 17 & 14.3 & $34.6 \pm 4.3^{\ddagger}$ \\
\hline \multicolumn{6}{|l|}{ Education } \\
\hline High school or lower & 649 & 52.8 & 94 & $14.5^{\dagger}$ & $36.9 \pm 4.5^{\ddagger}$ \\
\hline College or higher & 581 & 47.2 & 50 & 8.6 & $38.0 \pm 4.1$ \\
\hline \multicolumn{6}{|c|}{$\begin{array}{l}\text { Duration of residence in current location } \\
\text { (years) }\end{array}$} \\
\hline$\geq 2$ & 815 & 66.3 & 97 & 11.9 & $37.4 \pm 4.4$ \\
\hline$<2$ & 415 & 33.7 & 47 & 11.3 & $37.4 \pm 4.2$ \\
\hline \multicolumn{6}{|l|}{ Self-identified sexual orientation } \\
\hline Homosexual & 845 & 68.7 & 73 & 8.6 & $37.6 \pm 4.2$ \\
\hline Heterosexual & 17 & 1.4 & 6 & $35.3^{\ddagger}$ & $34.6 \pm 4.7^{\ddagger}$ \\
\hline Bisexual & 323 & 26.3 & 61 & 18.9 & $36.9 \pm 4.6$ \\
\hline Do not know & 45 & 3.7 & 4 & 8.9 & $39.2 \pm 3.1$ \\
\hline \multicolumn{6}{|c|}{$\begin{array}{l}\text { Being married or cohabitating/ } \\
\text { ever had sex with woman in past } 6 \text { months }\end{array}$} \\
\hline Homosexual & 878 & 71.4 & 74 & 8.4 & $37.8 \pm 4.3$ \\
\hline Bisexual & 352 & 28.6 & 70 & $19.9^{\ddagger}$ & $36.6 \pm 4.5^{\ddagger}$ \\
\hline \multicolumn{6}{|l|}{ Biological outcome } \\
\hline HIV status & & & & & \\
\hline
\end{tabular}


TABle 1: Continued.

\begin{tabular}{|c|c|c|c|c|c|}
\hline \multirow{2}{*}{ Variables } & \multicolumn{2}{|c|}{ Total } & \multicolumn{2}{|c|}{ Drinking ( $\geq 3$ times/week) } & \multirow{2}{*}{$\begin{array}{l}\text { Stigma and discrimination } \\
\qquad \pm \mathrm{SD}\end{array}$} \\
\hline & $N$ & $\%$ & $N$ & $\%$ & \\
\hline Negative & 1208 & 98.4 & 142 & 11.8 & $37.4 \pm 4.3$ \\
\hline Positive & 20 & 1.6 & 2 & 10.0 & $38.3 \pm 4.4$ \\
\hline \multicolumn{6}{|c|}{ Syphilis status } \\
\hline Negative & 1144 & 93.2 & 130 & 11.4 & $37.5 \pm 4.4$ \\
\hline Positive & 84 & 6.8 & 14 & 16.7 & $36.4 \pm 4.2^{*}$ \\
\hline
\end{tabular}

Total $N$ for each subgroup may not add up to the total due to missing data; P6M: in the past 6 months; ${ }^{*} P<0.05 ;{ }^{\dagger} P<0.01$; ${ }^{\ddagger} P<0.001$; NA: not applicable.

strong social pressure $[5,19]$. Such social environments may lead MSM to hide their sexual orientation by unwillingly engaging in heterosexual relationships [20]. Many of them continue to be married and maintain sexual relationships with their wives while maintaining concurrent but hidden homosexual relationships. Nearly one-third of MSM are married in China, and an even higher proportion reported having had sex with women [21, 22]. Our previous study showed approximately $40 \%$ of MSM being married or ever having had heterosexual behavior in Shandong province [23]. These bisexual and marital relationships have a strong impact on the HIV epidemic from MSM population to general population. Studies from different countries documented the high rate of unprotected sexual behaviors between spouses and/or regular heterosexual partners tends $[22,24,25]$. Therefore, bisexually active men in China could play a critical bridging role in spreading HIV and other STIs from their high-risk male sexual partners to low-risk female partners, for example, their wives $[26,27]$. Under social pressure, bisexual MSM may further reinforce the negative attitudes towards PLWHA and worsen drinking behaviors.

While stigma is widely invoked as a major facilitator of the HIV epidemic [28], only few studies have demonstrated an association between stigma and increased risk behavior. This study showed that unprotected male anal sex in the past 6 months and $\geq 2$ male sex partners in the past week are independently associated with drinking behavior and more negative attitudes towards PLWHA. Other studies that have demonstrated drinking behaviors will result in multiple sexual partners and unprotected sex [11, 12]. A cross-sectional study of MSM in 5 cities in Jiangsu province showed that heavy alcohol consumption was linked to unprotected anal intercourse $(\mathrm{OR}=2.32)$ compared with nondrinkers or light drinkers [29]. Alcohol consumption may directly impair judgment and cause social disinhibition, resulting in an increased likelihood of unprotected sexual encounters. The other explanation involves a social environment model, in which an association occurs because the social environment of drinking overlaps with an environment that facilitates meeting potential casual sexual partners. Stigma can have significant adverse effects on health and disease transmission by promoting delays in seeking care and reluctance to follow medical advice [28]. One study among Chinese migrants found that persons holding stigmatizing beliefs were more likely to have multiple sexual partners, a commercial sex partner, and a STI [30]. The findings of the present study suggest that common multiple sex partners and existing sexual network among this group could offer an intervention opportunity to reduce HIV/AIDS-related stigmatizing and discriminatory attitudes and strengthen alcohol use prevention and risk reduction initiatives among MSM.

This study also found that MSM who ever received peer education in the past year were more likely to express lower negative attitudes towards PLWHA. Peer education could relieve their social pressure, persuade MSM to receive HIV counseling and testing, and facilitate early diagnosis, timely prevention, and linkage to care and medical treatment. Ti and Kerr showed that by creating peer-involved HIV testing clinics and pairing physicians with peers, high-risk groups may be more likely to use these services without fear of being discriminated by healthcare workers [31]. By shifting delivery of care from healthcare professionals to peers, or by incorporating peer workers into professionally led services, a reduction in stigma and discrimination in these settings may be achieved. The findings of the present study underline the effect of peer education and the need to deliver conventional HIV/AIDS services directly to MSM to reduce the stigmatization and discrimination among MSM communities.

These studies highlighted the importance of policy considerations for stigma, alcohol use, and its related sexual risk among MSM. This study is not without limitations. First, the stigma scale may provoke socially desirable answers from respondents. Participants may feel embarrassed to openly express stigmatizing and discriminatory attitudes towards PLWHA during face-to-face interviews. This study might therefore underestimate the true levels of negative attitudes and risk behavior. Second, the nature of the cross-sectional study design precluded identification of causal relationships. Third, since this study did not assess the cooccurrence of drinking behavior with inconsistent condom use or multiple sex partners, any inference on the causal relationship between these variables is impossible. Fourth, the variables used to characterize alcohol consumption are not a complete list and may miss some opportunities to capture all true relationships.

Despite its many limitations, this study provides important information for further research and suggests that MSM who experience stigmatizing and discriminatory attitudes towards PLWHA and exhibit patterns of excessive alcohol use may be at higher risk for increased numbers of sexual partners and for bisexual and unprotected sex. Common HIV/AIDS-related stigmatizing and discriminatory attitudes, 
TABLE 2: Sex and drug use behavior, stigma and discrimination, alcohol consumption, HIV knowledge, and HIV prevention services among men who have sex with men in Shandong province, China.

\begin{tabular}{|c|c|c|c|c|c|}
\hline \multirow{2}{*}{ Variables } & \multicolumn{2}{|c|}{ Total } & \multicolumn{2}{|c|}{ Drinking ( $\geq 3$ times/week) } & \multirow{2}{*}{$\begin{array}{l}\text { Stigma and discrimination } \\
\qquad \pm \mathrm{SD}\end{array}$} \\
\hline & $N$ & $\%$ & $N$ & $\%$ & \\
\hline \multicolumn{6}{|c|}{ Sexual and drug use behaviors } \\
\hline \multicolumn{6}{|c|}{ Age of first sex (years) } \\
\hline$\leq 20$ & 661 & 53.7 & 70 & 10.6 & $38.0 \pm 4.1$ \\
\hline$>20$ & 569 & 46.3 & 74 & 13.0 & $36.7 \pm 4.6^{\ddagger}$ \\
\hline \multicolumn{6}{|c|}{ Sex with man in past 6 months } \\
\hline No & 105 & 8.6 & 6 & 5.7 & $39.4 \pm 3.2$ \\
\hline Yes & 1123 & 91.4 & 138 & 12.3 & $37.2 \pm 4.4^{\ddagger}$ \\
\hline \multicolumn{6}{|c|}{ Number of male sex partners in the past week } \\
\hline$<2$ & 499 & 45.7 & 43 & 8.6 & $38.8 \pm 3.9$ \\
\hline$\geq 2$ & 592 & 54.3 & 92 & $15.5^{\dagger}$ & $35.9 \pm 4.4^{\ddagger}$ \\
\hline \multicolumn{6}{|c|}{ Condom use during sex with man in the last sex } \\
\hline Yes & 794 & 70.8 & 89 & 11.2 & $37.6 \pm 4.3$ \\
\hline No & 327 & 29.2 & 48 & 14.7 & $36.4 \pm 4.5^{\ddagger}$ \\
\hline \multicolumn{6}{|c|}{ Condom use during sex with man in past 6 months } \\
\hline Always & 351 & 31.3 & 27 & 7.7 & $39.1 \pm 3.4$ \\
\hline Sometimes or never & 770 & 68.7 & 111 & $14.4^{\dagger}$ & $36.4 \pm 4.5^{\ddagger}$ \\
\hline \multicolumn{6}{|c|}{ Commercial sex with man in past 6 months } \\
\hline Yes & 306 & 27.2 & 51 & $16.7^{\dagger}$ & $35.7 \pm 4.2^{\ddagger}$ \\
\hline No & 818 & 72.8 & 86 & 10.5 & $37.8 \pm 4.3$ \\
\hline \multicolumn{6}{|c|}{$\begin{array}{l}\text { Condom use with paid male partner during the last } \\
\text { sex }\end{array}$} \\
\hline No & 84 & 6.8 & 18 & 21.4 & $34.3 \pm 4.4^{\ddagger}$ \\
\hline Yes & 222 & 72.5 & 33 & 14.9 & $36.2 \pm 4.0$ \\
\hline \multicolumn{6}{|c|}{$\begin{array}{l}\text { Condom use with paid male sex partners in past } 6 \\
\text { months }\end{array}$} \\
\hline Always & 91 & 29.8 & 12 & 13.2 & $38.4 \pm 3.4$ \\
\hline Sometimes or never & 214 & 70.2 & 38 & 17.8 & $34.5 \pm 4.0^{\ddagger}$ \\
\hline \multicolumn{6}{|c|}{ Sold sex to man in past 6 months } \\
\hline Yes & 264 & 21.5 & 43 & $16.3^{*}$ & $36.1 \pm 4.2^{\ddagger}$ \\
\hline No & 966 & 78.5 & 101 & 10.5 & $37.8 \pm 4.3$ \\
\hline \multicolumn{6}{|c|}{$\begin{array}{l}\text { Condom use in the last time with male partner who } \\
\text { sold sex }\end{array}$} \\
\hline No & 56 & 21.4 & 9 & 16.1 & $34.8 \pm 4.3^{\ddagger}$ \\
\hline Yes & 206 & 78.6 & 34 & 16.5 & $36.4 \pm 4.1$ \\
\hline \multicolumn{6}{|c|}{$\begin{array}{l}\text { Condom use in past } 6 \text { months with male partners } \\
\text { who sold sex }\end{array}$} \\
\hline Always & 82 & 31.1 & 12 & 14.6 & $38.8 \pm 3.2$ \\
\hline Sometimes or never & 182 & 68.9 & 31 & 17.0 & $34.9 \pm 4.1^{\ddagger}$ \\
\hline \multicolumn{6}{|c|}{ Sex with woman in past 6 months } \\
\hline Yes & 287 & 23.4 & 61 & $21.3^{\ddagger}$ & $36.8 \pm 4.5^{\dagger}$ \\
\hline No & 942 & 76.6 & 83 & 8.8 & $37.6 \pm 4.3$ \\
\hline \multicolumn{6}{|c|}{ Condom use with female partners in the last sex act } \\
\hline Yes & 149 & 52.1 & 23 & 15.4 & $37.7 \pm 4.1$ \\
\hline No & 137 & 47.9 & 37 & $27.0^{*}$ & $35.9 \pm 4.7^{\ddagger}$ \\
\hline \multicolumn{6}{|c|}{ Condom use with female partners in past 6 months } \\
\hline Always & 93 & 32.5 & 14 & 15.1 & $38.4 \pm 3.7$ \\
\hline Sometimes or never & 193 & 67.5 & 46 & 23.8 & $36.1 \pm 4.6^{\ddagger}$ \\
\hline
\end{tabular}


TABLE 2: Continued.

\begin{tabular}{|c|c|c|c|c|c|}
\hline \multirow{2}{*}{ Variables } & \multicolumn{2}{|c|}{ Total } & \multicolumn{2}{|c|}{ Drinking ( $\geq 3$ times/week) } & \multirow{2}{*}{$\begin{array}{l}\text { Stigma and discrimination } \\
\qquad \pm \mathrm{SD}\end{array}$} \\
\hline & $N$ & $\%$ & $N$ & $\%$ & \\
\hline \multicolumn{6}{|l|}{ Drug use } \\
\hline No & 1210 & 98.9 & 138 & 11.4 & $37.4 \pm 4.4$ \\
\hline Yes & 13 & 1.1 & 6 & $46.2^{\dagger}$ & $36.9 \pm 3.8$ \\
\hline \multicolumn{6}{|c|}{$H I V$-related prevention services in the past year } \\
\hline \multicolumn{6}{|c|}{ Condom promotion/VCT } \\
\hline Yes & 925 & 75.2 & 116 & 12.5 & $38.1 \pm 4.1$ \\
\hline No & 305 & 24.8 & 28 & 9.2 & $37.2 \pm 4.4^{\dagger}$ \\
\hline \multicolumn{6}{|c|}{ Received peer education } \\
\hline Yes & 508 & 41.3 & 69 & 13.6 & $38.7 \pm 4.0$ \\
\hline No & 722 & 58.7 & 75 & 10.4 & $36.5 \pm 4.3^{\ddagger}$ \\
\hline \multicolumn{6}{|c|}{ Had free HIV test in the past year } \\
\hline Yes & 624 & 50.7 & 87 & $13.9^{*}$ & $38.5 \pm 3.9$ \\
\hline No & 606 & 49.3 & 57 & 9.4 & $36.3 \pm 4.5^{\ddagger}$ \\
\hline \multicolumn{6}{|c|}{ Drink $\geq 3$ times per week in $P 6 M$} \\
\hline No & 1086 & 88.3 & - & - & $37.6 \pm 4.2$ \\
\hline Yes & 144 & 11.7 & - & - & $35.4 \pm 5.2^{\ddagger}$ \\
\hline
\end{tabular}

TABLE 3: Predictors for stigma and discrimination, alcohol consumption among men who have sex with men in Shandong province, China.

\begin{tabular}{|c|c|c|c|}
\hline Model 1 predictors for drink ( $\geq 3$ times per week in P6M) & $N(\%)$ & OR $(95 \% \mathrm{CI})$ & AOR $(95 \% \mathrm{CI})$ \\
\hline Higher level of stigma and discrimination (continuous) & $35.4 \pm 5.2$ & $0.90(0.86-0.93)^{\ddagger}$ & $0.92(0.87-0.96)^{\ddagger}$ \\
\hline Unprotected male anal sex in P6M & $111(14.4)$ & $2.0(1.3-3.1)^{\dagger}$ & $1.9(1.1-3.3)^{*}$ \\
\hline Bisexual identity/orientation & $70(19.9)$ & $2.7(1.9-3.8)^{\ddagger}$ & $2.2(1.3-3.9)^{\dagger}$ \\
\hline Number of male sex partners in the past week $\geq 2$ & $92(15.5)$ & $2.0(1.3-2.9)^{\dagger}$ & $1.5(1.0-2.4)^{*}$ \\
\hline Drug use & $6(46.2)$ & $6.7(2.2-20.1)^{\dagger}$ & $6.7(2.0-22.3)^{\dagger}$ \\
\hline High school or lower education level & $94(14.5)$ & $1.7(1.1-2.5)^{\dagger}$ & $1.6(1.0-2.6)^{*}$ \\
\hline Model 2 predictors for stigma and discrimination & Mean \pm SD & $\beta(95 \% \mathrm{CI})$ & Adjusted $\beta(95 \% \mathrm{CI})$ \\
\hline Drink $\geq 3$ times per week in $\mathrm{P} 6 \mathrm{M}$ & $35.4 \pm 5.2$ & $2.2(1.5-3.0)^{\ddagger}$ & $1.5(0.8-2.3)^{\ddagger}$ \\
\hline Unprotected male anal sex in P6M & $36.4 \pm 4.5$ & $2.8(2.2-3.3)^{\ddagger}$ & $1.7(1.1-2.2)^{\ddagger}$ \\
\hline Bisexual identity/orientation & $36.6 \pm 4.5$ & $1.2(0.6-1.7)^{\ddagger}$ & $0.9(0.4-1.4)^{\dagger}$ \\
\hline Number of male sex partners in past week $\geq 2$ & $35.9 \pm 4.4$ & $2.9(2.4-3.4)^{\ddagger}$ & $1.9(1.3-2.4)^{\ddagger}$ \\
\hline Commercial sex with man in $\mathrm{P} 6 \mathrm{M}$ & $35.7 \pm 4.2$ & $2.1(1.5-2.6)^{\ddagger}$ & $0.8(0.2-1.4)^{\dagger}$ \\
\hline Never received peer education in the past year & $36.5 \pm 4.3$ & $2.3(1.8-2.7)^{\ddagger}$ & $1.7(1.2-2.2)^{\ddagger}$ \\
\hline
\end{tabular}

Multivariable logistic regression analysis was applied for alcohol consumption (Model 1); multivariable linear regression model was performed for stigma and discrimination (Model 2); P6M: in the past 6 months; OR: odds ratio; 95\% CI: confidence interval; AOR: adjusted odds ratio; ${ }^{*} P<0.05 ;{ }^{\dagger} P<0.01 ;{ }^{\ddagger} P<0.001$.

drinking behaviors, bisexual identity, and unprotected sex among this group have become emerging challenges in containing the HIV epidemic. The findings of this study highlight the urgent need to develop programs that would target HIV/AIDS-related stigmatizing and discriminatory behavior and strengthen alcohol use prevention and risk reduction strategies among MSM, in the context of rapid social changes that are occurring in China.

\section{Conflict of Interests}

The authors declare that there is no conflict of interests regarding the publication of this paper.

\section{Acknowledgments}

This study was supported, in part, by the National Center for AIDS/STD Control and Prevention of the China Center for Disease Control and Prevention (CDC), the Shandong Province Center for Disease Control and Prevention, the Jinan Prefecture CDC, the Qingdao Prefecture CDC, and the Yantai Prefecture CDC.

\section{References}

[1] China CDC, National Behavioral and Biological Surveillance Report 2012, National Center for AIDS/STD Control and Prevention, China CDC, Beijing, China, 2012. 
[2] Ministry of Health and Joint United Nations Programme on HIV/AIDS, 2011 Estimates for the HIV/AIDS Epidemic in China, 2012.

[3] F. van Griensven, J. W. D. L. van Wijngaarden, S. Baral, and A. Grulich, "The global epidemic of HIV infection among men who have sex with men," Current Opinion in HIV and AIDS, vol. 4, no. 4, pp. 300-307, 2009.

[4] C. Wei, T. E. Guadamuz, R. Stall, and F. Y. Wong, "STD prevalence, risky sexual behaviors, and sex with women in a national sample of Chinese men who have sex with men," American Journal of Public Health, vol. 99, no. 11, pp. 1978-1981, 2009.

[5] B. Zhang, X. Li, and T. Shi, "A preliminary estimate to population size of MSM, and HIV infection rate among MSM in China," Chinese Journal of AIDS/STDs, vol. 8, pp. 197-199, 2002.

[6] A. H. Grossman, "Gay men and HIV/AIDS: understanding the double stigma," The Journal of the Association of Nurses in AIDS Care, vol. 2, no. 4, pp. 28-32, 1991.

[7] X. Li, H. Lu, X. Ma et al., "HIV/AIDS-related stigmatizing and discriminatory attitudes and recent HIV testing among men who have sex with men in Beijing," AIDS and Behavior, vol. 16, no. 3, pp. 499-507, 2012.

[8] G. Letamo, "Prevalence of, and factors associated with, HIV/AIDS-related stigma and discriminatory attitudes in Botswana," Journal of Health, Population and Nutrition, vol. 21, no. 4, pp. 347-357, 2003.

[9] B. L. Genberg, Z. Hlavka, K. A. Konda et al., "A comparison of HIV/AIDS-related stigma in four countries: negative attitudes and perceived acts of discrimination towards people living with HIV/AIDS," Social Science \& Medicine, vol. 68, no. 12, pp. 22792287, 2009.

[10] W. Hao, Z. Su, and H. Chen, "Drinking and drinking-lelated problems in China," Japanese Journal of Alcohol Studies \& Drug Dependence, vol. 42, no. 6, pp. 595-601, 2007.

[11] A. K. Matthews, Y. I. Cho, T. Hughes, S. C. Wilsnack, T. Johnson, and K. Martin, "The relationships of sexual identity, hazardous drinking, and drinking expectancies with risky sexual behaviors in a community sample of lesbian and bisexual women," Journal of the American Psychiatric Nurses Association, vol. 19, no. 5, pp. 259-270, 2013.

[12] R. L. Cook and D. B. Clark, "Is there an association between alcohol consumption and sexually transmitted diseases? A systematic review," Sexually Transmitted Diseases, vol. 32, no. 3, pp. 156-164, 2005.

[13] B. L. Genberg, S. Kawichai, A. Chingono et al., "Assessing HIV/AIDS stigma and discrimination in developing countries," AIDS and Behavior, vol. 12, no. 5, pp. 772-780, 2008.

[14] A. P. Mahajan, J. N. Sayles, V. A. Patel et al., "Stigma in the HIV/AIDS epidemic: a review of the literature and recommendations for the way forward," AIDS, vol. 22, supplement 2, pp. S67-S79, 2008.

[15] K. Ford, D. N. Wirawan, G. M. Sumantera, A. A. S. Sawitri, and M. Stahre, "Voluntary HIV testing, disclosure, and stigma among injection drug users in Bali, Indonesia," AIDS Education and Prevention, vol. 16, no. 6, pp. 487-498, 2004.

[16] A. E. Rudolph, W. W. Davis, V. M. Quan et al., "Perceptions of community- and family-level injection drug user (IDU)- and HIV-related stigma, disclosure decisions and experiences with layered stigma among HIV-positive IDUs in Vietnam," AIDS Care: Psychological and Socio-Medical Aspects of AIDS/HIV, vol. 24, no. 2, pp. 239-244, 2012.
[17] S. C. Kalichman, L. C. Simbayi, M. Kaufman, D. Cain, and S. Jooste, "Alcohol use and sexual risks for HIV/AIDS in sub-saharan Africa: systematic review of empirical findings," Prevention Science, vol. 8, no. 2, pp. 141-151, 2007.

[18] J. C. Fisher, H. Bang, and S. H. Kapiga, "The association between HIV infection and alcohol use: a systematic review and metaanalysis of African studies," Sexually Transmitted Diseases, vol. 34, no. 11, pp. 856-863, 2007.

[19] W. T. Steward, P. Miege, and K. H. Choi, "Charting a moral life: the influence of stigma and filial duties on marital decisions among Chinese men who have sex with men," PLoS ONE, vol. 8, no. 8, Article ID e71778, 2013.

[20] S. I. Khan, N. Hudson-Rodd, S. Saggers, and A. Bhuiya, "Men who have sex with men's sexual relations with women in Bangladesh," Culture, Health and Sexuality, vol. 7, no. 2, pp. 159169, 2005.

[21] Z. Beichuan, L. Dianchang, L. Xiufang, and H. Tiezhong, "A survey of men who have sex with men: Mainland China," American Journal of Public Health, vol. 90, no. 12, pp. 1949-1950, 2000.

[22] K.-H. Choi, D. R. Gibson, L. Han, and Y. Guo, "High levels of unprotected sex with men and women among men who have sex with men: a potential bridge of HIV transmission in Beijing, China," AIDS Education and Prevention, vol. 16, no. 1, pp. 19-30, 2004.

[23] M. Liao, D. Kang, B. Jiang et al., "Bisexual behavior and infection with HIV and syphilis among men who have sex with men along the east coast of China," AIDS Patient Care and STDs, vol. 25, no. 11, pp. 683-691, 2011.

[24] C. Folch, G. Marks, A. Esteve, K. Zaragoza, R. Muñoz, and J. Casabona, "Factors associated with unprotected sexual intercourse with steady male, casual male, and female partners among men who have sex with men in Barcelona, Spain," AIDS Education and Prevention, vol. 18, no. 3, pp. 227-242, 2006.

[25] A. L. Hernandez, C. P. Lindan, M. Mathur et al., "Sexual behavior among men who have sex with women, men, and Hijras in Mumbai, India-multiple sexual risks," AIDS and Behavior, vol. 10, supplement 4, pp. S5-S16, 2006.

[26] J. T. F. Lau, M. Wang, H. N. Wong et al., "Prevalence of bisexual behaviors among men who have sex with men (MSM) in China and associations between condom use in MSM and heterosexual behaviors," Sexually Transmitted Diseases, vol. 35, no. 4, pp. 406-413, 2008.

[27] Q. He, Y. Wang, P. Lin et al., "Potential bridges for HIV infection to men who have sex with men in Guangzhou, China," AIDS and Behavior, vol. 10, supplement 4, pp. S17-S23, 2006.

[28] S. Bharat, "A systematic review of HIV/AIDS-related stigma and discrimination in India: current understanding and future needs," SAHARA-J: Journal of Social Aspects of HIV/AIDS, vol. 8, no. 3, pp. 138-149, 2011.

[29] J. Jiang, N. Cao, J. Zhang et al., "High prevalence of sexually transmitted diseases among men who have sex with men in Jiangsu Province, China," Sexually Transmitted Diseases, vol. 33, no. 2, pp. 118-123, 2006.

[30] H. Liu, X. Li, B. Stanton et al., "Relation of sexual risks and prevention practices with individuals' stigmatising beliefs towards HIV infected individuals: an exploratory study," Sexually Transmitted Infections, vol. 81, no. 6, pp. 511-516, 2005.

[31] L. Ti and T. Kerr, "Task shifting redefined: removing social and structural barriers to improve delivery of HIV services for people who inject drugs," Harm Reduction Journal, vol. 10, no. 1, article 20, 2013. 


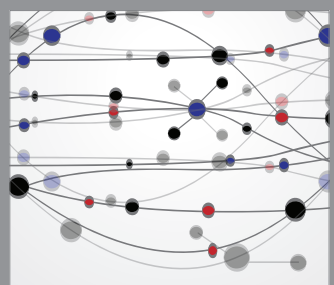

The Scientific World Journal
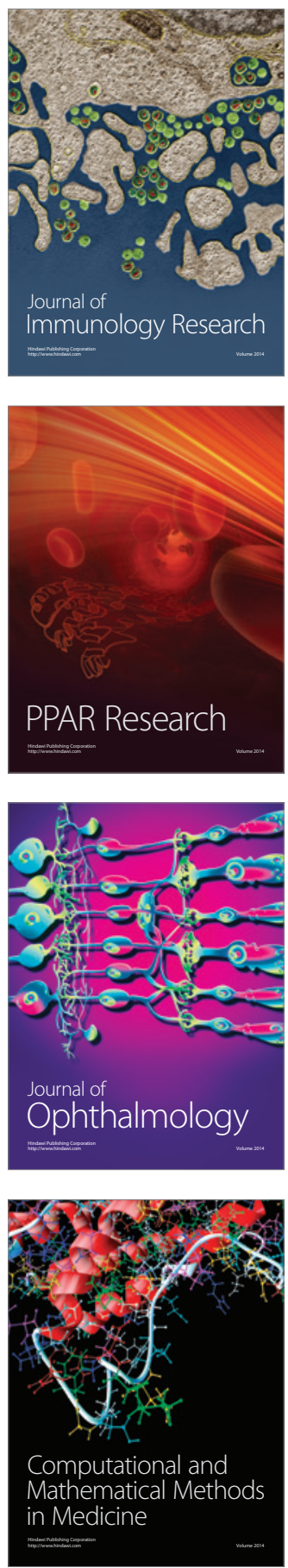

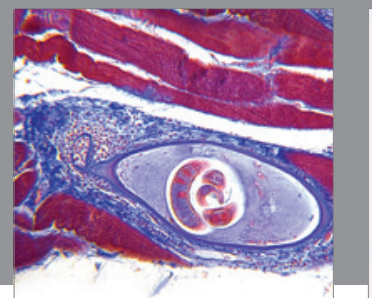

Gastroenterology

Research and Practice
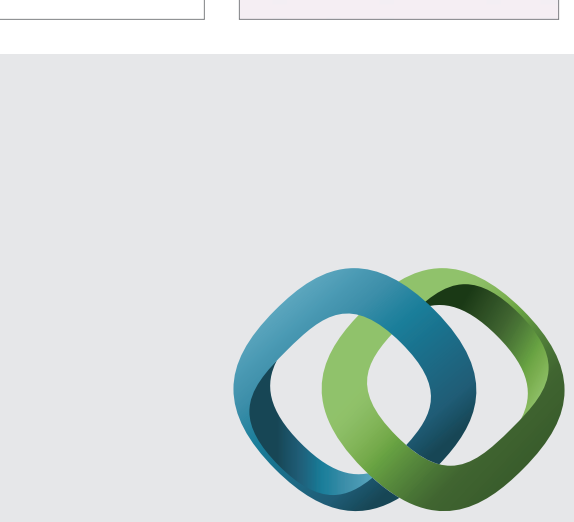

\section{Hindawi}

Submit your manuscripts at

http://www.hindawi.com
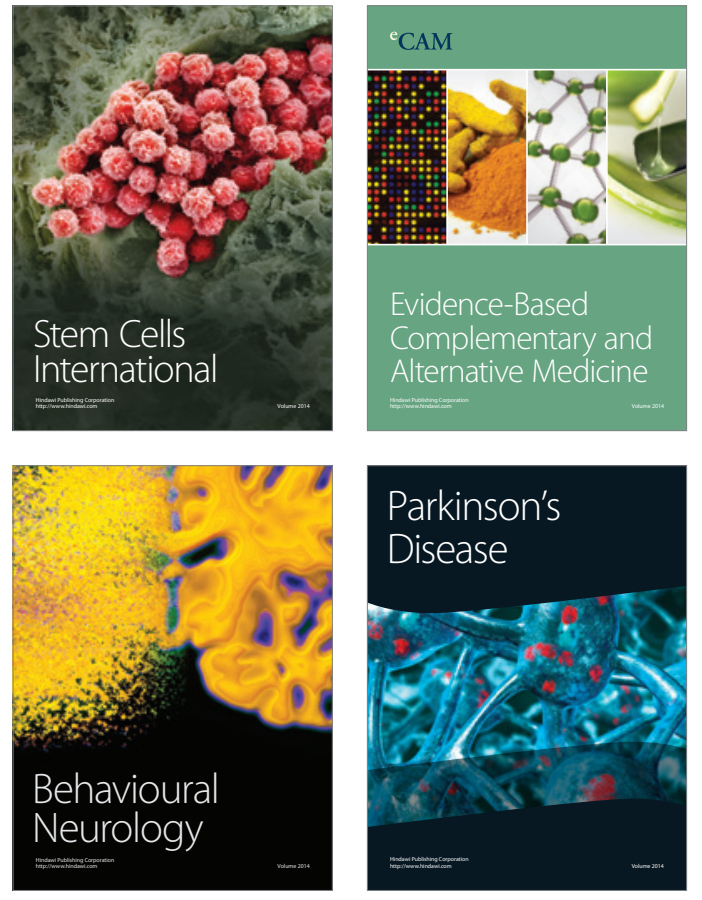
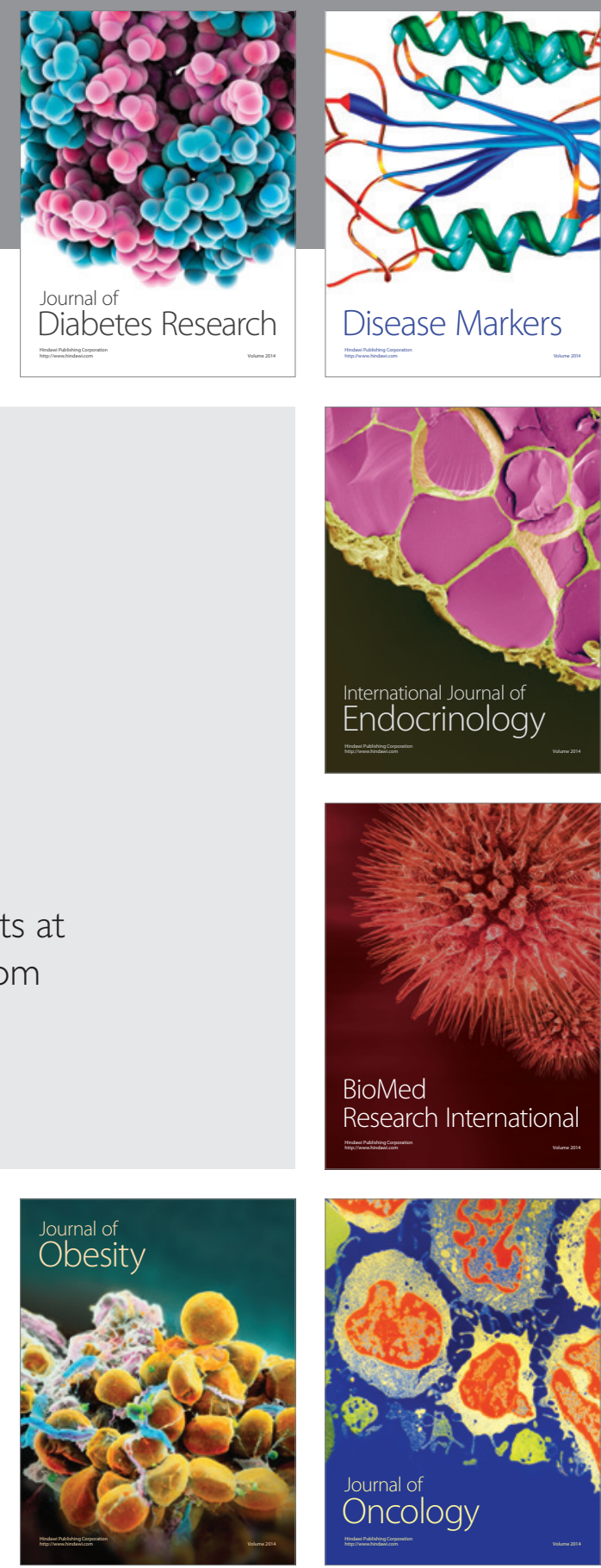

Disease Markers
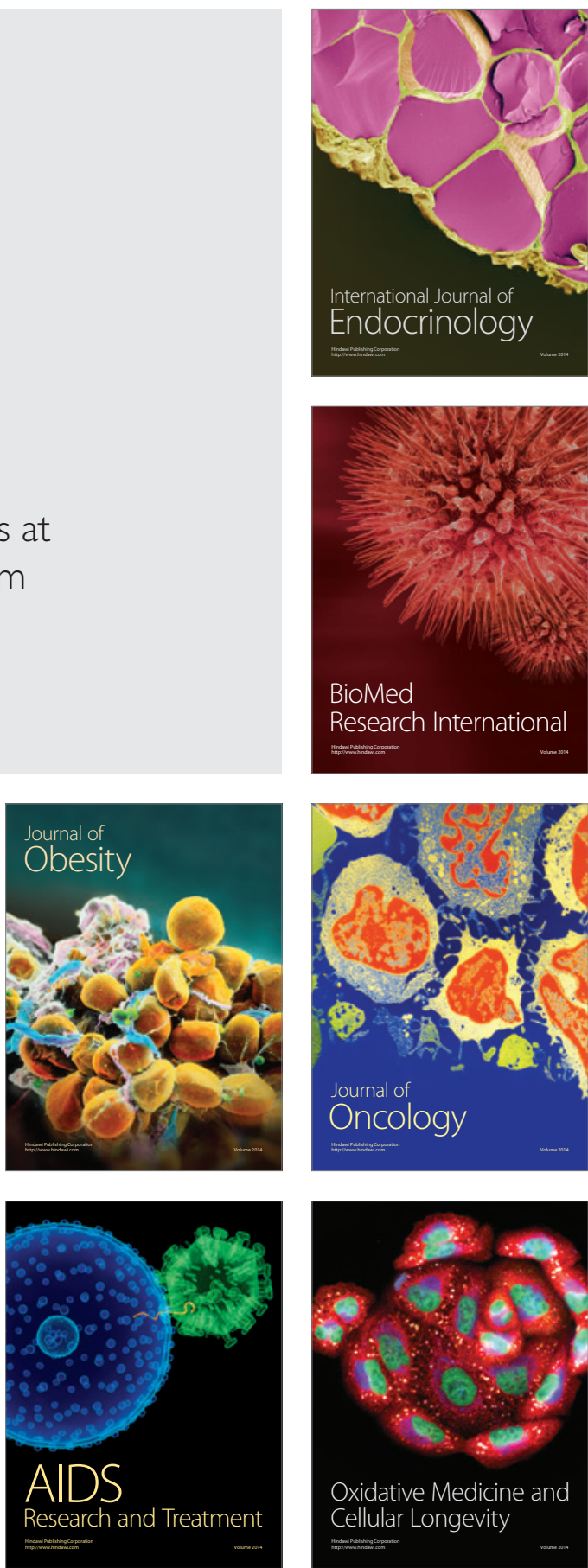